\begin{tabular}{|c|l|}
\hline Title & Unified Constitutive Model Considering Equivalence of Back Stress Due to Plastic and Viscoplastic Deformation \\
\hline Author(s) & Mayama, Tsuy oshi; Sasaki, Katsuhiko; Ishikawa, Hiromasa \\
\hline Citation & Engineering Plasticity from Macroscale to Nanoscale Pts 1 and 2, 83-88 \\
\hline Issue Date & 2003 \\
\hline Doc URL & http:/hdl.handle.net/2115/15885 \\
\hline Rights & the original is available online at www.scientific.net \\
\hline Type & article (author version) \\
\hline Note & Key Engineering Materials, Volume 233-236 \\
\hline Information & EPMN2003.pdf \\
\hline
\end{tabular}

Instructions for use 


\title{
Unified Constitutive Model Considering Equivalence of Back Stress Due to Plastic and Viscoplastic Deformation
}

\author{
Tsuyoshi Mayama $^{1}$, Katsuhiko Sasaki $^{1}$ and Hiromasa Ishikawa ${ }^{1}$ \\ ${ }^{1}$ Division of Mechanical Science, Hokkaido University, \\ N13, W8, Kita-ku, Sapporo, 060-8628, Japan
}

Keywords: Constitutive model, Plasticity, Creep, Back stress

\begin{abstract}
This paper treats a unified constitutive model for the viscoplastic and creep deformations. First, experimental observations on the correlation between back stress due to plasticity and creep are carried out using Type 304 stainless steel at room temperature. The experimental results show that there is the equivalence of back stress due to plastic and creep deformation. Then considering the equivalence of back stress, a unified constitutive model for plasticity and viscoplasticity is proposed. To verify the applicability of this model, the numerical simulations are conducted by the model, and compared with the experiments.
\end{abstract}

\section{Introduction}

The back stress plays an important role to explain the plastic deformation, in particular in cyclic plasticity, and almost all constitutive models for the cyclic plasticity utilize the back stress[1,2,3]. The constitutive models of the cyclic plasticity were originally developed for time independent deformation. However, to apply the constitutive models to estimate fatigue failure, including creep-fatigue interaction, the constitutive model must also describe viscoplastic deformation such as creep and stress relaxation. Then, the evolution equation of the back stress should be taken into accounts of the effects of both plasticity and creep. One question is whether the back stress developed by creep deformation is of the same value as that developed by the plastic deformation $[4,5,6]$.

In this paper, a unified constitutive model for plastic and creep deformation is proposed. First, in order to observe the correlation between back stress affecting plasticity and creep, creep tests during pure tension are conducted. The experiments show that there is equivalence of back stress in plasticity and creep. Considering the equivalence of the back stress due to plasticity and creep, the unified constitutive model is constructed. The applicability of the model is also verified by the numerical simulations of several tests of (i) pure tension, (ii) pure creep, (iii) cyclic tension-compression loading with constant strain amplitudes under constant strain rates, and (iv) intermittent creep tests during cyclic loading. The experiments are conducted using thin tubular specimens of Type 304 stainless steel at room temperature.

\section{Experimental Material and Method}

The specimen used in this study is a drawing tube of Type 304 stainless steel subjected to a solution

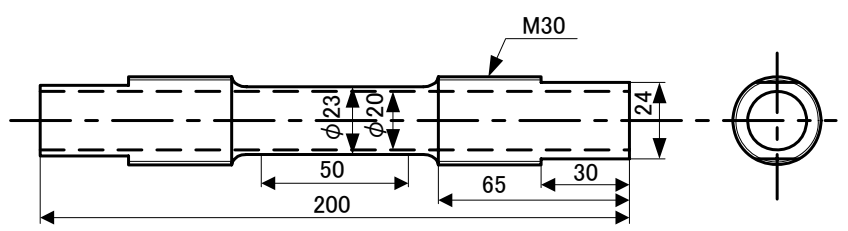

Fig.1 Geometry of specimen
Table1 Test conditions of intermittent creep

\begin{tabular}{c|c|c|c}
\hline Strain amplitude [\%] & \multicolumn{3}{|c}{0.5} \\
\hline Strain rate [\%/sec] & 0.1 & 0.01 & 0.001 \\
\hline Stress Level [MPa] & $100,200,250,275$ \\
\hline
\end{tabular}




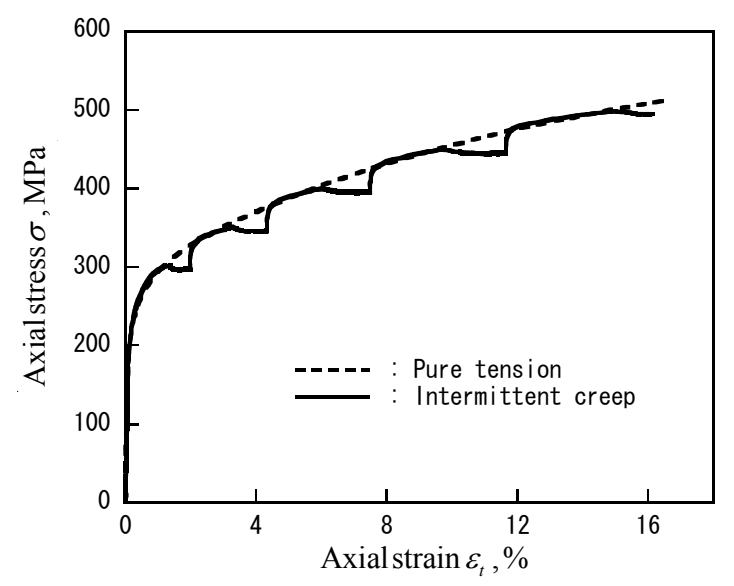

Fig.2 Stress-strain curves of pure tension and intermittent creep during pure tension heat treatment. The drawing tube has a $32 \mathrm{~mm}$ outer diameter and $6 \mathrm{~mm}$ wall thickness and is annealed by the manufacturer at $1070{ }^{\circ} \mathrm{C}$ followed by water quenching for half an hour. Its chemical compositions are $0.02 \mathrm{C}, 0.45 \mathrm{Si}$, 1.09Mn, 0.030P, 0.005S, $8.30 \mathrm{Ni}, 18.54 \mathrm{Cr}$, and $\mathrm{Fe}$ balanced in weight percent. The tubular specimens are machined from this tube as shown in Fig.1. The specimens are fabricated by metal cutting and then annealed to get an initial isotropic stress state. In this annealing process, the specimens are heated and maintained at $380{ }^{\circ} \mathrm{C}$ for $120 \mathrm{~min}$ followed by air cooling. Young's modulus of the specimen at room temperature is $\mathrm{E}=200 \mathrm{GPa}$.

A servo-controlled axial-torsional testing machine are used for computerized testing data and data acquisition. Strain is measured using two strain gauges applied on diametrically opposite side of the specimen. The axial force is measured using the load cell incorporated in the machine.

There are four types of test in this work: (i) pure tension tests under stress rates of 5 and $0.5 \mathrm{MPa} / \mathrm{sec}$; (ii) creep tests during 300 seconds at stress levels of 250, 275 and $300 \mathrm{MPa}$; (iii) cyclic tension-compression loading tests with a constant strain amplitude under a constant strain rate; and (iv) intermittent creep tests during cyclic tension-compression loading. Here, tests (iii) and (iv) are conducted successively as follow. First, the specimens are subjected to cyclic loading with a constant strain amplitude. After stabilization of the stress-strain curve, the intermittent creep tests are conducted at the four stress levels as shown in Table 1.

\section{Equivalence of back stress due to plasticity and creep}

In Fig.2, a solid line represents the stress-strain curve of pure tension and the broken lines represent intermittent creep tests during pure tension. The pure tension are conducted under the stress rate of $10 \mathrm{MPa} / \mathrm{sec}$, and the intermittent creep tests are conducted for 300 seconds at the stress levels of 300 , 350,400 and $450 \mathrm{MPa}$ during the pure tension loading under the stress rate of $10 \mathrm{MPa} / \mathrm{sec}$. When loading state changes to pure tension under $10 \mathrm{MPa} / \mathrm{sec}$ after intermittent creep at each stresses, the stress-strain curves after the intermittent creep coincide with that of the pure tension without creep as shown in Fig.2. This result shows that the strain hardening occurs during creep although the stress keeps constant, and the amount of strain hardening during creep is as same as that during the pure tension without creep. Namely the experiments suggest that the development of the back stress during the pure tension equals to that during the intermittent creep. Considering the equivalence of the back stress a unified constitutive model is constructed as the below section.

\section{Formulation of Unified Constitutive Model}

The viscoplastic potential is defined as in chaboche [7].

$$
\mathrm{F}=\frac{\mathrm{H}}{\mathrm{n}+1}\left\langle\frac{\bar{\sigma}-\mathrm{R}}{\mathrm{H}}\right\rangle^{\mathrm{n}+1}
$$


where \langle\rangle is MacAuley bracket and defined as $\langle x\rangle=\frac{1}{2}(x+|x|) . \mathrm{H}$ is the drug stress, $\mathrm{R}$ is the flow stress and $\mathrm{n}$ is the material constant. The equivalent stress $\bar{\sigma}$ in Eq.(1) is represented as

$$
\bar{\sigma}=\sqrt{\frac{3}{2}\left(s_{i j}-\alpha_{i j}^{\prime}\right)\left(s_{i j}-\alpha_{i j}^{\prime}\right)}
$$

where $s_{i j}$ and $\alpha_{i j}^{\prime}$ are the deviatoric components of the stress tensor $\sigma_{i j}$ and the kinamatic back stress tensor $\alpha_{i j}$, respectively.

The normality hypothesis now becomes

$$
\dot{\varepsilon}_{i j}^{v}=\frac{\partial \mathrm{F}}{\partial \sigma_{i j}}=\left\langle\frac{\bar{\sigma}-\mathrm{R}}{\mathrm{H}}\right\rangle^{n} \frac{\sigma_{i j}-\alpha_{i j}}{\bar{\sigma}}
$$

The modified viscoplastic work rate is defined as the following equation.

$$
\dot{W}^{v}=\bar{\sigma} \dot{\bar{\varepsilon}}^{v}=\left(\sigma_{i j}-\alpha_{i j}\right) \dot{\varepsilon}_{i j}^{v}
$$

Then, from Eqs.(3) and (4), the following equation is given.

$$
\dot{\bar{\varepsilon}}^{v}=\left\langle\frac{\bar{\sigma}-\mathrm{R}}{\mathrm{H}}\right\rangle^{\mathrm{n}}
$$

From Eqs.(3) and (5), the flow rule can be explained by

$$
\dot{\varepsilon}_{i j}^{v}=\frac{\dot{\bar{\varepsilon}}^{v}}{\bar{\sigma}}\left(\sigma_{i j}-\alpha_{i j}\right)
$$

From Eq.(6) the equivalent strain rate can be described as the follow;

$$
\dot{\bar{\varepsilon}}^{v}=\sqrt{\dot{\varepsilon}_{i j}^{v} \dot{\varepsilon}_{i j}^{v}}
$$

The following Ziegler's type of assumption for the evolution equation of the kinematic back stress is used here.

$$
\dot{\alpha}_{i j}=\left(\sigma_{i j}-\alpha_{i j}\right) \dot{\mu}
$$

where $\dot{\mu}$ is the scalar multiplying factor which is determined from Eqs.(2),(5) and (8). Eventually, the kinematic back stress rate is represented by

$$
\dot{\alpha}_{i j}=\left[\frac{\sigma_{k l}-\alpha_{k l}}{\bar{\sigma}^{2}}-\frac{\mathrm{H} \ddot{\bar{\varepsilon}}^{v}}{\mathrm{n} \overline{\bar{\sigma}}}\left(\dot{\bar{\varepsilon}}^{v}\right)^{\frac{1-\mathrm{n}}{\mathrm{n}}}-\frac{\dot{\mathrm{R}}}{\bar{\sigma}}\right]\left(\sigma_{i j}-\alpha_{i j}\right)
$$

In this paper, the following power law is used to represent the nonlinear viscoplastic modulus simply, 


$$
\hat{\varepsilon}^{v}=\frac{\mathrm{K}}{\mathrm{E}}\left(\frac{\hat{\sigma}}{\mathrm{D}}\right)^{m} \hat{\sigma}
$$

where $\mathrm{E}$ is Young's modulus and $\mathrm{K}$ is a material constant. $\hat{\varepsilon}^{v}$ is the equivalent viscoplastic strain measured from $\varepsilon_{i j}^{R}$, which is the viscoplastic strain just before the loading direction change. And $\hat{\sigma}$ is in general represented as,

$$
\hat{\sigma}=\left[\frac{3}{2}\left(s_{i j}-\hat{\alpha}_{i j}^{\prime}\right)\left(s_{i j}-\hat{\alpha}_{i j}^{\prime}\right)\right]^{1 / 2}
$$

where $\hat{\alpha}_{i j}^{\prime}$ is the deviatoric components of the center of the current yield surface $\hat{\alpha}_{i j}$ before the loading direction change. The back stress $\alpha_{i j}$ is memorized as $\hat{\alpha}_{i j}$ when the loading direction changes.

Since, during the current loading the residual viscoplastic strain $\varepsilon_{i j}^{R}$ is constant, $\dot{\varepsilon}_{i j}^{v}$ is equals to $\dot{\hat{\varepsilon}}_{i j}^{v}$ and $\dot{\bar{\varepsilon}}^{v}=\dot{\hat{\varepsilon}}^{v}$ from $\varepsilon_{i j}^{v}=\hat{\varepsilon}_{i j}^{v}+\varepsilon_{i j}^{R}$, Eqs.(10) and (11) give

$$
\dot{\bar{\varepsilon}}^{v}=\dot{\hat{\varepsilon}}^{v}=\frac{\mathrm{K}}{\mathrm{E}}(\mathrm{m}+1)\left(\frac{\hat{\sigma}}{\mathrm{D}}\right)^{\mathrm{m}} \frac{1}{\hat{\sigma}}\left[\frac{3}{2}\left(\sigma_{i j}^{\prime}-\alpha_{i j}^{\prime}\right) \dot{\sigma}_{i j}^{\prime}\right]=\left\langle\frac{\bar{\sigma}-\mathrm{R}}{\mathrm{H}}\right\rangle^{n}
$$

In Eqs.(10) and (12), D and $\mathrm{m}$ are the functions depending on the accumulated inelastic strain at the memorized point. They can be explained by

$$
\begin{aligned}
& \mathrm{D}=\mathrm{D}_{(i)}\left\{1-\alpha \exp \left(-\int_{i-1} \dot{\bar{\varepsilon}}^{v} d t / a\right)\right\} \\
& \mathrm{m}=\mathrm{m}_{(i)}\left\{1-\beta \exp \left(-\int_{i-1} \dot{\bar{\varepsilon}}^{v} d t / b\right)\right\}
\end{aligned}
$$

where $\mathrm{D}_{(i)}$ and $\mathrm{m}_{(i)}$ become $\mathrm{D}_{1}$ and $\mathrm{m}_{1}$ during the initial loading before the loading direction changes, $\mathrm{D}_{2}$ and $\mathrm{m}_{2}$ after the first loading direction change, and $\mathrm{D}_{0}$ and $\mathrm{m}_{0}$ after the second loading direction change, respectively.

\section{Discussions}

Pure Tensile Tests Fig. 3 shows the stress-strain curves of the pure tensile tests under the stress rates of $0.5 \mathrm{MPa} / \mathrm{sec}(\circ)$ and $5 \mathrm{MPa} / \mathrm{sec}(\square)$, respectively. The solid lines represent the stress-strain curves simulated by the proposed model. It can be seen that the simulations have a good agreement with the experiments. The material constants used in the simulation are shown in Table 2. $\mathrm{D}_{1}$ has the strain rate dependence and the value of $\mathrm{D}_{1}$ are calculated from the following equation.

$$
\mathrm{D}_{1}=185-18.3 \exp \left(-\frac{\dot{\varepsilon}}{1.45 \times 10^{-4}}\right)
$$

Table2 Material constants

\begin{tabular}{c|c|c|c|c|c|c|c|c|c|c|c|c|c}
\hline $\mathrm{E}[\mathrm{Gpa}]$ & $\mathrm{K}[\mathrm{MPa}]$ & $\mathrm{H}[\mathrm{MPa}]$ & $\mathrm{R}_{0}[\mathrm{MPa}]$ & $\mathrm{n}$ & $\lambda$ & $\mathrm{c}$ & $\alpha$ & $\mathrm{a}$ & $\mathrm{m}_{1}$ & $\mathrm{~m}_{2}$ & $\mathrm{~m}_{0}$ & $\beta$ & $\mathrm{b}$ \\
\hline 200 & 0.05 & 130 & 110 & 10 & 0.26 & 0.002 & 0.3 & 0.04 & 8 & 5 & 5 & 0.1 & 0.02 \\
\hline
\end{tabular}




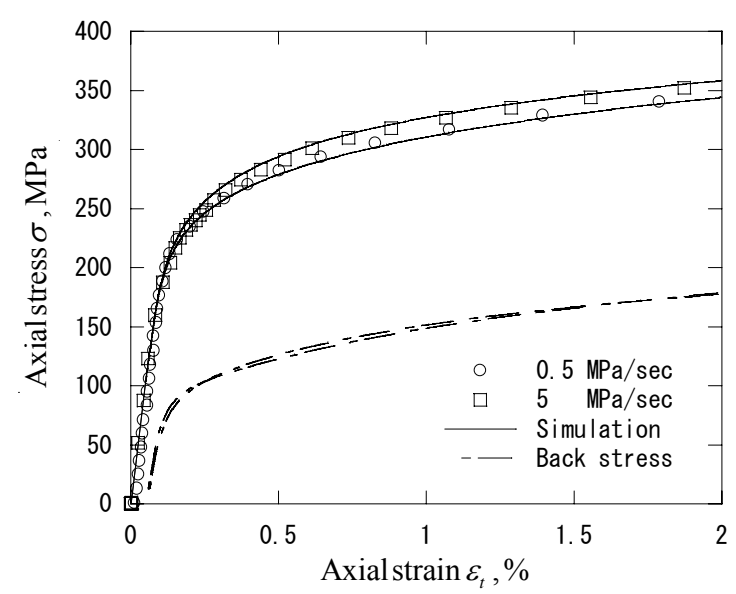

Fig.3 Stress-strain curves of pure tension

Creep Tests Fig. 4 shows the creep curves during 300 seconds at the stress levels of 250, 275 and $300 \mathrm{MPa}$ after the tensile loading under the stress rate of $5 \mathrm{MPa} / \mathrm{sec}$ with three nontested original specimens. The solid lines represent the creep curves simulated by the proposed model. Because of the equivalence of the back stress in plastic deformation and creep as mentioned above, the back stress calculated by the pure tension is used in this simulation. The simulations have good agreements with the experiments.

Cyclic loading and Intermittent Creep Test Figure 5 shows the stress-strain curve of the intermittent creep tests at the stress levels of $\mathrm{a}(100 \mathrm{MPa}), \quad \mathrm{b}(200 \mathrm{MPa}), \quad \mathrm{c}(250 \mathrm{MPa}), \quad$ and $\mathrm{d}(275 \mathrm{MPa})$ after the stabilization of the cyclic tension-compression preloading with the strain amplitude of $0.5 \%$ under the strain rate of $0.01 \% / \mathrm{sec}$.

At first the simulation of the cyclic tension-compression loading is conducted. In Fig.6, the symbol (०) shows the stabilized stress-strain curve of the cyclic tension-compression loading, and the solid line shows the simulated stress-strain curve. The simulation has a good agreement with the experiment. The material constants $\mathrm{D}_{2}$ and $\mathrm{D}_{0}$ have the strain rate dependence and the value of $\mathrm{D}_{2}$ and $\mathrm{D}_{0}$ are calculated by the following equations.

$$
\begin{aligned}
& \mathrm{D}_{2}=191.5-14 \exp \left(-\frac{\dot{\varepsilon}}{1.3 \times 10^{-4}}\right) \\
& \mathrm{D}_{0}=243-17 \exp \left(-\frac{\dot{\varepsilon}}{1.3 \times 10^{-4}}\right)
\end{aligned}
$$

Figure 7 shows the creep curves of the intermittent creep tests during 300 seconds at the stress levels of $100 \mathrm{MPa}(\circ), 200 \mathrm{MPa}(\square), 250 \mathrm{MPa}(\diamond)$, and $275 \mathrm{MPa}(\times)$. Experimental results show that 


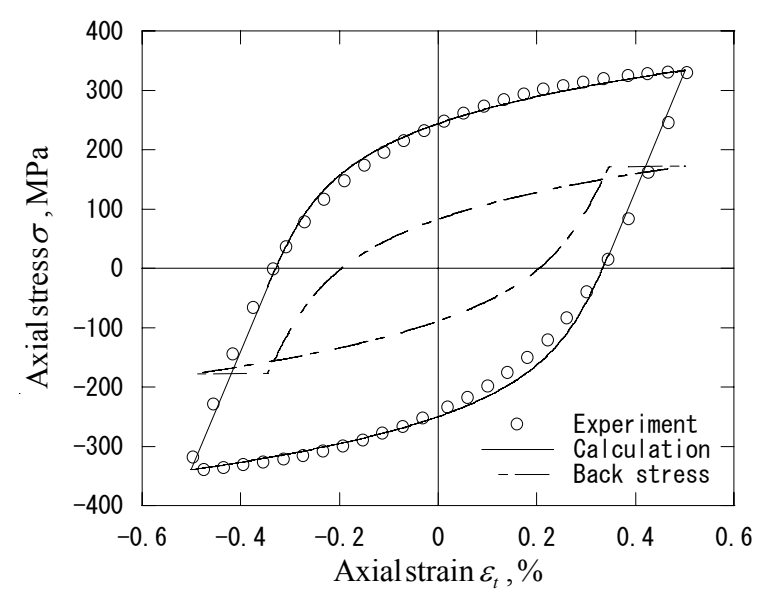

Fig.6 Tension-compression cyclic loading (Strain amplitude $=0.5 \%$, Strain rate $=0.01 \% / \mathrm{sec}$ )

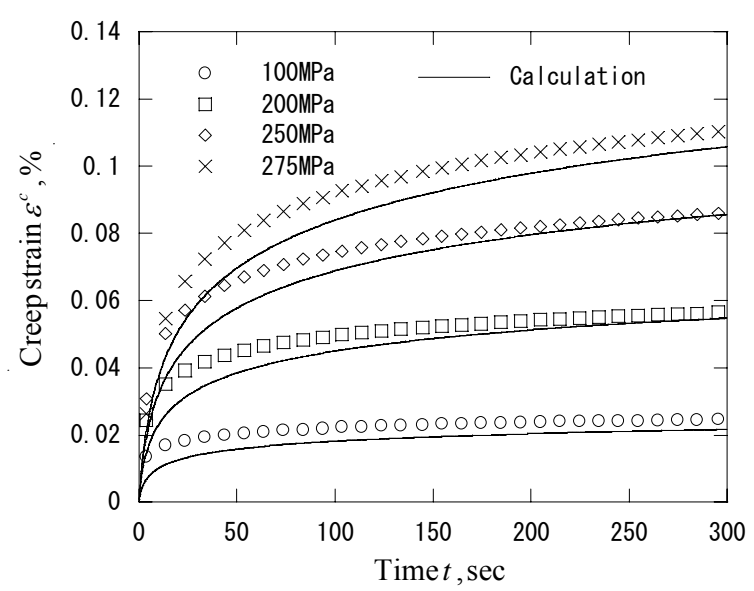

Fig.7 Creep curves of intermittent creep (Strain amplitude $=0.5 \%$, Strain rate $=0.01 \% / \mathrm{sec})$

the intermittent creep curves are almost saturated in 300 seconds, and the creep strain of the intermittent creep is much less than that of the creep with the nontested original specimen as shown in Fig.4. This result suggests the back stress during the intermittent creep is not same value as that during pure creep. Considering the equivalence of the back stress, the simulations of the intermittent creep curve are carried out. The simulations shown by solid lines in Fig.7 have good agreements with the experiments.

\section{Conclusions}

This paper discussed the construction of a unified constitutive model to describe the interaction between plastic and creep deformations. As a results, the following conclusions were obtained:

(1) The creep test during pure tension suggests the equivalence of the back stress due to plasticity and creep.

(2) Considering the equivalence of the back stress in plasticity and creep, a unified viscoplastic constitutive model is constructed from the flow rule obtained by the viscoplstic potential, the evolution equation by Ziegler rule, and the viscoplastic modulus by the power law.

(3) The material constants can be simply obtained from the pure tension and the cyclic tension-compression loading tests.

(4) The consideration of the equivalence of the back stress gives good description of the creep in the nontested original specimens and the intermittent creep during the cyclic tension-compression loading.

\section{References}

[1] Freed, A.D. and Walker, K.P.: Int. J. Plast. Vol.9 (1993), pp.213

[2] Estrin, Y. et. al.: Trans. ASME, J. Eng. Mat. and Technol. Vol.118(1996), pp.441

[3] Ohno, N. and Wang, J.D.: Eur. J. Mech. A/Solids Vol.13(1994), pp.519

[4] Ishikawa, H. and Sasaki, K.: Trans. ASME J. Eng. Mat. and Technol. Vol.116(1994), pp.133

[5] Ishikawa, H. et. al.: IUTAM Symposium on Creep in Structures, pp.391

[6] Sasaki, K. and Ishikawa, H.: JSME Int. J. Series A Vol.38(1995), pp.265

[7] Chaboche, J.L.: Int. J. Plast. Vol.5 (1989), pp.247 
